\title{
Macroeconomics of Regional Integration: Withdrawal from a Customs Union
}

\author{
Ali M. El-Agraa \\ Fukuoka University \\ Anthony J. Jones \\ University of Leeds
}

\begin{abstract}
This paper has two unique features: it deals with withdrawal from a customs union, which is a neglected aspect of international economic integration, and does so within a macroeconomic framework rather than standard general-partial equilibrium analysis. Withdrawal was in the British Labour Party's 1983 election manifesto; Greenland actually withdrew from the European Communities in 1985; presently an influential section of the British Conservative Party and others wish to do so for the UK; and the European Union's Reform Treaty for the first time allows for it. Moreover, given the recent proliferation in preferential trading arrangements, with overlap in membership, withdrawal is on the horizon. A simple, almost nä̈ve, macroeconomic framework is tailored for the purpose not only because of its direct policy relevance, but also because it adds variety to relevant discussion. The conclusion reached is that the model does not negate the general conclusion of the orthodox analysis: in the presence of constraints on the use of domestic and exchange-rate policies to achieve full employment, the model points to the general potential superiority of continued customs union membership over a policy of withdrawal.
\end{abstract}

\footnotetext{
*Corresponding address: Professor Ali M. El-Agraa, Faculty of Commerce, Fukuoka University, 8-19-1 Nanakuma, Jonan-ku, Fukuoka 814-0180, Japan, Tel:81-92-871-6631, Fax: 81-92-864-2938, E-mail: elagraa@fukuoka-u.ac.jp. Anthony J. Jones was Dean of Undergraduate Studies, Leeds University Business School, Leeds LS2 9JT, UK.
} 


\section{- JEL classification: F15}

- Keywords: International Economic Integration, Macroeconomic Modelling, Withdrawal from a Customs Union

\section{Introduction}

For the first time in the history of the European Union (EU), Article I-59 of the shelved constitutional treaty extended the right to any member state to secede from the union. This article is however maintained in the Reform Treaty, agreed in June $2007^{1}$ and finalised in October 2007, but it is yet to be ratified before becoming EU law; a treaty which largely retains the essentials of the constitutional treaty, deleting only its controversial 'federalist' overtones. This development ushers in a new area for research in the field of international economic integration since the literature has for all intents and purposes been confined to the 'joining', not the 'withdrawing' from schemes of preferential trading arrangements (see, inter ali, El-Agraa, 2007). Also, withdrawal from the EU is not merely a theoretical possibility: Greenland actually left the European Community (EC) ${ }^{2}$, the EU's predecessor; the British Labour Party proposed it in its manifesto for the 1983 general election; a large section of the present United Kingdom (UK) Conservative Party desires it and so does one minor party whose only aim is to do precisely that; and so on and so forth. It is even given academic credibility by Minford et al (2005) who advocate it for the UK, as well as other EU member nations, since they are adamant that the UK has incurred costs due to EU membership in practically every sector of the economy ${ }^{3}$. One may even add to this list the proposal by the Scottish Nationalist

This came about largely because of the efforts of German Chancellor Angela Merkel who had put the revival of the stalled EU constitutional treaty at the top of her agenda for the EU presidency for the first six months of 2007. One must however give due credit to both the moral as well as the openly-aired endorsement and collaboration of the present president of the EU Commission, Mr José Manuel Barroso.

${ }^{2}$ Greenland initially voted against joining the EEC when Denmark acceded in 1973, but because Denmark as whole voted to join, Greenland, as a part of Denmark, also had to likewise. When home rule for Greenland commenced in 1979, the country held a new referendum and voted for exit from the EEC. After a period of wrangling over fishing rights, in 1985 the 'Territory' left the EEC. However, it remains subject to the EU treaties through the EU's Association of Overseas Countries and Territories. This was permitted by the Greenland Treaty, a special treaty signed in 1984 to allow the withdrawal.

${ }^{3}$ We are not suggesting that we agree with either the methodology adopted by the Minford et al (2005), or their findings, but this is not the place to go through these issues. 
Party to take Scotland out of UK, although in this case one would be going beyond the standard 'free trade areas' (FTAs), 'customs unions' (CUs), 'common markets' (CMs) and 'economic unions' (EcUs).

Thus the purpose of this paper is to advance a theoretical model that can be used to evaluate the economic consequences of withdrawal from a CU. We begin by setting the scene before going on to develop a macroeconomic model and stating our conclusions.

\section{Setting the Scene}

It is now a clearly established result of the orthodox theory of international economic integration that, given a world plagued with protectionism, the potential welfare level for the whole of the customs union $(\mathrm{CU})$ is higher than the sum of the welfare levels available to countries following unilateral policies ${ }^{4}$. Of course, it is quite possible, as whenever the gains from collusive action are contemplated, that the political feasibilities for the actual distribution of the gains may not prove sufficient to ensure that all the participants believe that they have received a fair share of those gains or even to ensure that each single participant does in fact benefit compared to the possibilities available to that country through unilateral action. Similarly, although the theoretical potential superiority of membership of a CU (likewise, the enlargement of existing CUs) has been established, it may be the case that constraints on policy choice at the appropriate level of economic integration cause actual policies within the union to fall further away from the theoretically optimal configuration that would be the case for purely national policies. It then follows that a second-best case could be made for withdrawal from a $\mathrm{CU}$, as per the cases mentioned in the introduction. This case relies on the empirical argument, which would have to be carefully evaluated in each case, that within the existing constraints of policy-making, attainable unilateral action may be superior to the results achieved by continued membership of the union.

However, as has been well demonstrated, the first-best solution within such a framework is to improve joint policymaking within the union and to seek successful cooperation with countries outside the union. Given the heroic abstractions from reality made in neoclassical trade theory, such conclusions are vulnerable to charges of irrelevance particularly insofar as, in most standard

\footnotetext{
${ }^{4}$ There is no need to provide a full list of contributions to date on this; those interested should consult ElAgraa (2007).
} 
presentations at least, full employment is assumed to exist at all times in all countries.

It is therefore proposed to tackle the problem here in the context of a simple, almost naïve, macroeconomic approach to $\mathrm{CU}$ theory which, contrary to the orthodox approach, is based on the assumption of the existence of unemployment within each economy. This approach was pioneered by El-Agraa (1981) and Jones (1982) and it is its extension and development which provides the theoretical foundation for the subsequent argument presented here. In short, the aim of this paper is to advance a macroeconomic approach to $\mathrm{CU}$ theory but in a context which deals with withdrawal from a CU rather than with the formation of CUs (the literature on which is now quite extensive - see, inter alia, El-Agraa (1989; 1999; 2007)), thus introducing a refreshing change without deviating from our main task: the argument for joining a $\mathrm{CU}$ is almost a mirror image of what is presented here. Lest we be misunderstood, our claim is that we are simply providing an alternative and simple model with the aim of extending the discussion within a $\mathrm{CU}$ aspect which is rarely discussed; we are not claiming that our model should be the be all and end all.

\section{The Basic Macroeconomic Framework}

The basic macroeconomic framework is a Keynesian one. To simplify the analysis, it is assumed that:

(a) Money wage rates are fixed in each of the three countries (1,2 and 3 which stand respectively for $H$, the home country, $P$, the potential CU partner, and $W$, the rest of the world) for the period under consideration.

(b) The marginal product of labour $(L)$ is everywhere constant.

(c) Monetary, fiscal and exchange-rate policies in each country are also fixed at levels which are regarded by the national governments as providing the best feasible configuration of such policies which they can achieve.

(d) Initially, 1 and 2 impose a common external tariff rate (CET), $t^{*}$, on trade with 3 and 3 imposes the same rate on its imports from 1 and 2 .

It follows from these assumptions that the various commodities produced within any economy can be grouped together, via the 'composite commodity' theorem, to form a single aggregate national product for which units of measurement can be chosen so that, for each economy, the factor cost price of a unit of its national product is one (measured in any one currency). With the further simplifying 
assumptions that there are no internal sales or other indirect taxes, that transport costs are zero and that, within each country, the market prices of each national product differ from factor cost prices only be the amount of any import duty, it follows that the consequences of withdrawal from the $\mathrm{CU}$ flow from the effects that this policy has on the market prices of each national product in each of the three separate economies identified in the model.

Of course, the great unknown in analysing the consequences of one country's withdrawal from a $\mathrm{CU}$ is the reaction to this by other countries but, in order to keep the argument within manageable proportions, the analysis will initially focus on the case in which withdrawal from the $\mathrm{CU}$ is accomplished by the adoption by both 1 and 2 of the existing CET $\left(t^{*}\right)$ to apply to their mutual trade flows and to keep on applying it to trade with 3.

Given the assumptions of the model, such a policy change will have no (immediate) impact on the market prices of the domestic output in 1 and 2 or on any prices within 3. Accordingly, the immediate consequences of 1's withdrawal from the $\mathrm{CU}$ can be summarised as working through the changes in the market prices within 1 and 2 on their mutual trade, i.e.

$$
\Delta P_{12} / P_{12}=\Delta P_{21} / P_{21}=+t^{*}>0,
$$

where $P_{i j}$ is the market price of country $j$ 's product in country $i$.

Following the standard macroeconomic treatment of the commodity market, the consequential changes in national output can be evaluated by use of the equilibrium conditions:

$$
\Delta Y_{i}=\Delta C_{i}+\Delta I_{i}+\Delta G_{i}+\Delta M_{j i}+\Delta M_{k j}-\Delta M_{i j}-\Delta M_{i k},
$$

where $Y_{i}, C_{i}, I_{i}$, and $G_{i}$, are, respectively, national output, private consumption, private net investment and government expenditure on goods and services in 1, all measured at constant factor prices of unity, and where $M_{i j}$ is the factor cost measure of 1's imports from country $j$ and hence, equally, of country $j$ 's exports to country $i$.

To simplify the argument further, it is assumed that the import content of exports, $I$, and $G$ is zero, that, initially at least, $I$ is unaffected by the price changes resulting from the change in trade barriers and that $G$ is subject to the requirements of a balanced budge so that:

$$
\Delta G_{i}=t_{i} \Delta Y_{i}+\Delta T_{i j}^{*}+\Delta T_{i k}^{*}
$$

where $0<t_{i}<1$ is the (constant) marginal rate of direct taxation in country $i$ and $T_{i j}^{*}$ is the tariff revenue collected by country $i$ on its imports from country $j$.

It is also assumed that:

$$
\Delta C_{i}=c_{i} \Delta Y_{i}-\Delta T_{i j}^{*}
$$


where $0<c_{i}<1$, and hence that the change in real domestic expenditure $\left(\Delta E_{i}=\right.$ $\left.\Delta C_{i}+\Delta I_{i}+\Delta G_{i}\right)$ is dependent solely on any changes in factor income which result from the formation of the $\mathrm{CU}$, i.e.

$$
\Delta E_{i}=e_{i} \Delta Y_{i}
$$

where $0<e_{i}=c_{i}+t_{i}<1$ is the marginal propensity to spend in country $i$.

There are a number of possible ways of modelling expenditure on imports but here it is helpful to use a two-stage share-of-expenditure import function which can be derived from the nested CES utility function originally suggested by Verdoorn and Schwartz (1972) following the work of Armington (1969), i.e.

$$
M_{i j}^{*}=u_{i}^{\delta i}\left(P_{i}^{m} / P_{i j}\right)^{\delta i-1} M_{i}^{*}
$$

with

$$
M_{i}^{*}=v_{i}^{\varepsilon i}\left(P_{i} / P_{i}^{m}\right)^{\varepsilon i-1} C_{i}^{*},
$$

where $0<\mathrm{u}_{\mathrm{i}}, \mathrm{v}_{\mathrm{i}}<1$ are the parameters reflecting the strength of preferences in country $i$ between competing imports and between all imports and domestic output respectively; $\delta_{\mathrm{i}} \geq \varepsilon_{\mathrm{i}}>1$ are the elasticities of substitution between competing imports and between domestic output and total imports respectively (the restriction that both elasticities exceed unity has been made to simplify the subsequent argument but, although the assumption appears empirically plausible, it should be noted that it is in fact critical to the validity of the general conclusions reached here and that it has a theoretical significance which can be compared with the results of McMillan and McCann, 1981); and $P_{i}$ and $P_{1}^{m}$ are domestic cost-of-living and import prices indices defined to be consistent with the aggregation of national products implied by the underlying utility function. Accordingly, the market price changes resulting from 1's withdrawal from the CU as summarised in (1), can also be represented as having the following effects on the domestic cost-of-living and import prices indices in both 1 and 2 (for $i=1,2$ ):

$$
\Delta P_{i}^{m} / P_{i}^{m}=\mu_{i j} t^{*}>0,
$$

and

$$
\Delta P_{i} / P_{i}=\lambda_{i j} t^{*}>0
$$


where $0<\mu_{i j}=M_{i j}^{*} / M_{i}^{*}<1$ is the share of the total expenditure on imports in country $i$ devoted to imports from its former partner $j$; and $0<\lambda_{i j}=M_{i j}^{*} / C_{i}^{*}<1$ is similarly the share of total consumption at market prices in country $i$ taken by the national product of its former partner $j$.

The total differentiation of $(5 \mathrm{a}, \mathrm{b})$ when combined with $(5 \mathrm{c}, \mathrm{d})$ yields the following results for the change in expenditure in either 1 or 2 on imports from 3 :

$$
\Delta M_{13}^{*}=\lambda_{13} \Delta C_{i}^{*}+C_{i}^{*} \Delta \lambda_{13}
$$

where

$$
C_{i}^{*} \Delta \lambda \mu_{i 3}^{*}=t^{*} M_{i 3}^{*}\left[\left(\delta_{i}-\varepsilon_{i}\right) \mu_{i j}+\left(\varepsilon_{i}-1\right) \lambda_{i j}\right]>0
$$

Since domestic expenditure on imports also includes the payment of tariff revenue collected by the government of the importing country, the actual change in imports (at factor cost prices) to either 1 or 2 from 3 can be identified as:

$$
\Delta M_{i 3}=m_{i 3} \Delta Y_{i}+C_{i}^{*} \Delta \lambda_{13} /\left(1+t^{*}\right)
$$

where $0<m_{i 3}=\lambda_{i 3} c_{i} /\left(1+t^{*}\right)<1$ is the marginal propensity of country $i$ to import from 3 .

It can be seen from (6c) that the change in demand for imports from 3 can be split into two major components. The first term on the right-hand side is dependent on the ultimate change in national income and may be viewed as a secondary effect induced by whatever changes in income result from the primary price effects of the break up of the CU. It seems appropriate in the context of the withdrawal of 1 from the $\mathrm{CU}$ to define the reverse price effects as the 'trade diversion reversal effect' $\left(d_{i}\right)$, i.e.

$$
d_{i}=C_{i}^{*} \Delta \lambda_{13} /\left(1+t^{*}\right)=t^{*} M_{i 3}\left[\left(\delta_{i}-\varepsilon_{i}\right) \mu_{i j}+\left(\varepsilon_{i}-1\right) \lambda_{i j}\right]>0
$$

Total differentiation of $(5 \mathrm{a}, \mathrm{b})$ also enables the change in trade flows between 1 and 2 to be identified as:

$$
\Delta M_{i j}=\Delta M_{i j}^{*}-\Delta T_{i j}^{*}=\lambda_{i j} \Delta C_{i}^{*}-C_{i}^{*} \Delta \lambda_{i j}-C_{i}^{*} \Delta \lambda^{i 3}-\Delta T_{i j}^{*}
$$


since, by definition, $\Delta \lambda_{i j}=-\Delta \lambda_{i j}-\Delta \lambda_{i 3}$. As the change in tariff revenue on trade between 1 and 2 can be identified as:

$$
\Delta T_{i j}^{*}=t^{*} \Delta m_{i j}+t^{*} M_{i j}
$$

it follows that (8a) can be rewritten as:

$$
\Delta M_{i j}=m_{i j} \Delta Y_{i}-r_{i}-d_{i}-t^{*} M_{i j}
$$

where $0<m_{i j}=\lambda_{i j} c_{i} /\left(1+t^{*}\right)<1$ is the marginal propensity in country $i$ to import from its former partner; and $t^{*} M_{i j}$ is the (notional) value of the tariff revenue which could be received by $i$ if the new tariff on trade with its former partner was levied on the volume of trade which existed prior to 1's withdrawal from the CU. In addition to the 'trade diversion reversal effect,' $d_{i},(8 \mathrm{~b})$ also contains one further term:

$$
r_{i}=C_{i}^{*} \Delta \lambda_{i i} /\left(1+t^{*}\right)=t^{*} M_{i j}\left(\varepsilon_{i}-1\right) \lambda_{i i} .
$$

We call this the 'trade reduction effect' since it measures, at factor cost prices, the effect on imports from the partner due to the increased share in domestic expenditure gained by domestic output at the expense of imports from the partner. As such, it can also be viewed as a domestic output and employment creation effect; such an increased share of the domestic market seems to lie at the heart of the protectionist case for import controls. In order to see whether this view is justified in this model, however, it is necessary both to complete the formal framework and to solve the model.

\section{Completing and Solving the Model}

The first of these tasks is simply achieved by noting that since (by assumption) imports into 3 are unaffected by any price changes, the effects on the trade flows depend solely on income changes, i.e.

$$
\Delta M_{3 i}=m_{3 i} \Delta Y_{3},
$$

where $0<m_{3 i}=\lambda_{3 i} c_{i} /\left(1+t^{*}\right)<1$ is the marginal propensity of 3 to import from country $i$. 
The solution of the model is then obtained by substitution of (3), (4), (6c), (7a), (8b) and (10) into (2) and can be summarised as:

$$
\Delta Y_{i}=K_{1 i} F_{1}+K_{2 i}+K_{3 \mathrm{i}} \mathrm{F}_{3},
$$

where $K_{i j}$ are the multipliers of the primary effects $\left(F_{i}\right)$ resulting from 1 's withdrawal from the CU. For both 1 and 2 these primary effects can be identified as:

$$
F_{i}=-d_{j}-\left(r_{j}-r_{i}\right)-t^{*}\left(M_{j i}-M_{i j}\right)
$$

whilst, for 3,

$$
F_{3}=d_{1}+d_{2} .
$$

The multipliers all involve complex combinations of the parameters but fortunately their signs can be evaluated, as in Jones (1982), from the general restrictions placed in the range of values taken by the parameters. Thus, by defining $0<h_{i}=1-e_{i}<1$ as the marginal propensity to hoard and $0<b_{i}=h_{i}+m_{i j}$ $+m_{i k}<1$ as the marginal propensity not to spend on domestic output, it can be shown that all multipliers can be expressed in the form:

$$
K_{j i}=\alpha_{j i} / D
$$

where

$$
D=h_{i} \alpha_{i i}+m_{i j}\left(\alpha_{i i}-\alpha_{j i}\right)+m_{i k}\left(\alpha_{i i}-\alpha_{k i}\right)
$$

where

and where

$$
\alpha_{i i}=b_{k}\left(h_{j}+m_{j i}\right)+m_{j k}\left(h_{k}+m_{k i}\right)
$$

It then follows that

$$
\alpha_{j i}=m_{k i} m_{j k}+m_{j i} b_{k}
$$

$$
\alpha_{i i}>\alpha_{j i}>0
$$

that $D>0$ and that accordingly the multipliers $K_{i i}$ and $K_{i j}$ are unambiguously positive whilst, equally clearly, $K_{i i}>K_{j i}$.

By substitution of $(7 \mathrm{a}, \mathrm{b})$ into (11), it is then possible to identify the effects of withdrawal from the $\mathrm{CU}$ on output (and hence, by implication, employment) in 1:

$$
\begin{array}{r}
\Delta Y_{i}=-\left(K_{11}-K_{31}\right) \mathrm{d}_{2}-\left(K_{21}-K_{31}\right) d_{1} \\
-\left(K_{11}-K_{21}\right)\left[t^{*}\left(M_{21}-M_{12}\right)+r_{2}-r_{1}\right] .
\end{array}
$$


From the restrictions so far placed on the value of both multipliers and multiplicands it can be seen that the first term in (11a), i.e. the 'trade diversion reversal effect' in the partner, is a certain source of loss for 1 . In order for the policy of withdrawal to make economic sense for 1 within the framework of this model, it is therefore necessary that the remaining two terms should be sufficient sources of gain to outweigh these losses. Although it is theoretically possible that this could be the case, the general presumption here is that this is highly unlikely.

Consider first the second terms in (11a), i.e. the consequential change in the income of 1 which results from the 'trade diversion reversal effect' in that country. It is intuitively improbable that this could have any significant effect in that country itself simply because its direct effects are felt only in the former partner (which suffers a decline in aggregate demand) and in 3 (which benefits from a gain in aggregate demand). Thus the only effects in 1 depend on the relative strengths of the 'repercussion' effects for 1 which stem from the direct changes in the other countries. Formally this is shown by the fact that the sign of $\left(K_{21}-K_{31}\right)$ is the same as the sign of $\left[m_{21}\left(1-e_{3}\right)-m_{31}\left(1-e_{2}\right)\right]$. This will only be of a significant negative value (which is the requirement for $d$ to have a significant positive effect on home output) if the marginal propensity to import from 1 and the marginal propensity to spend are much lower in 1 than in 3 . Although this is a theoretical possibility which could be explored for any specific case, there is no reason to believe that this is likely to be of any general significance and, indeed, if El-Agraa's (1979) suggested basic set of hypothetical but representative values for the parameters is employed, the multiplier $\left(K_{21}-K_{31}\right)$ is zero.

With regard to the last term in (11a), since the multiplier, $\left[-\left(K_{11}-K_{21}\right)\right]$ is unambiguously negative, the possibility of 1 gaining from the policy of withdrawal is seen to depend on whether the multiplicand $\left[t^{*}\left(M_{21}-M_{12}\right)+r_{2}-r_{1}\right]$ is also negative. Proponents of a UK withdrawal from the European Community did in fact point to one component in the multiplicand which does have such a negative effect. This is $\left(-r_{1}\right)$, (the negative of ) the 'trade reduction effect' in 1 which provides a stimulus to domestic output as domestic demand switches away from imports from 2 towards domestic output in 1. A crucial feature of the model, however, is to suggest that the 'trade reduction effect' in 2 must also be taken into consideration and that this directly offsets the 'trade reduction effect' in 1. Indeed, if the definition of the 'trade reduction effect' ( $7 b)$ is employed, the final multiplicand in (11a) can be rewritten as:

$$
\left.t^{*}\left[M_{21}-M_{12}\right)+M_{21} \lambda_{22}\left(\varepsilon_{2}-1\right)-M_{12} \lambda_{11}\left(\varepsilon_{1}-1\right)\right]
$$


which, in the neutral case of initial trade flows between 1 and 2 being balanced, simplifies further to:

$$
t^{*} M_{12}\left[\lambda_{22}\left(\varepsilon_{2}-1\right)-\lambda_{11}\left(\varepsilon_{1}-1\right)\right] .
$$

Such an expression will be significantly negative only if the share of total expenditure devoted to domestic output and the elasticity of substitution between domestic output and imports is far higher in 1 than in 2.

Even if 1 did gain, however, it is important to recognise that the same multiplicand is present but with signs reversed in determining the outcome for the former partner. Thus, if the policy of withdrawal is to have any benefit for 1, this will be so only as a result of a 'beggar-thy-neighbour' effect on the former partner.

Of course, if it is believed that 2 will not retaliate to 1's withdrawal from the $\mathrm{CU}$ and will continue to offer free access to its market whilst 1 raises its tariff barriers on imports, both $r_{2}$ and $d_{2}$ will be zero as will $t^{*} M_{21}$ and there would be a very good chance that the beneficial effects for 1 or $r_{1}$ would outweigh any adverse effects which might arise from the 'trade diversion reversal effect' $\left(d_{1}\right)$ in that country. The same applies to any further unilateral increases to trade barriers since these will increase the size of $r_{1}$ and the resultant gain to 1 becomes larger. Needless to add, any such gains remain 'beggar-thy-neighbour' effects and are dependent on the assumption of no significant retaliation by 2 .

\section{Withdrawal and the Balance of Payments}

The above conclusion applies even when the assumption is combined with the argument that higher tariff barriers should be used to remove the balance-ofpayments constraint on expansionary domestic policies so that foreign retaliation would be unjustified as total imports would remain unaltered. Such an argument implies rather more faith in the accuracy of the timing and the estimation of the effects of different kinds of policy and in the sympathetic understanding of foreign governments than seems justified - see El-Agraa (1979a; 1984a; 1989) for further discussion of this. In addition, it fails to recognize the discriminatory change associated with withdrawal from a CU.

Thus consider the basic case analysed above in which the primary effects of 1's withdrawal from the CU on its balance of trade (at the pre-withdrawal income level) can be identified as:

$$
\left[r_{1}-r_{2}+t^{*}\left(M_{12}-M_{21}\right)-d_{2}\right] .
$$


It is impossible to identify the sign of this effect with complete generality but there is a presumption that it would be negative because, whereas the trade reduction and tariff revenue effects tend to be offset directly by their counterparts in 2 , the loss to 1 of the 'trade discrimination reversal effect' in 2 has no impact. Thus, in general, the consequence of withdrawal from a CU could be expected to be a worsening rather than an improvement in any balance-of-payments constraint. The same would be equally true for 2 , whilst it is 3 which could be expected to gain.

If domestic expansion to full employment is constrained for both 1 and 2 by the balance of payments and unwillingness or inability to use devaluation of the exchange rate, the model clearly points to the superiority of continued membership of the CU in which domestic expansion is combined with an expenditure-switching policy by the $\mathrm{CU}$ as a whole. In the absence of the possibility of devaluation, perhaps the most obvious expenditure-switching policy for the $\mathrm{CU}$ is the raising of its CET.

Of course, at least two major problems arise with such a policy. The first is the possibility of retaliation by 3 . This may indeed be a real danger which might effectively make such a policy option counter-productive. However, if 1 and 2 are genuinely constrained from reaching full employment by balance-of-payments considerations, then, unless 3 is willing to countenance some form of expenditureswitching policy which the CU members could adopt, the problem must be traced to this source and the solution to the global problem of payments adjustments should be sought on an appropriately wider scale. Failing such a solution, however, continued membership of the CU does still offer at least two potential advantages over withdrawal. The first concerns the relative bargaining strength (in a world where retaliatory action is common) of a CU compared with individual members each acting alone. The second concerns the fact that, with membership of the CU, both 1 and 2 will have lower marginal propensities to import from 3 than otherwise would be the case. Accordingly, domestic expansionary policies within the $\mathrm{CU}$ will have less adverse effects on such members' balance of payments vis-à-vis 3 than would be the case in non-membership of the CU.

This point, however, leads to the second major problem associated with the possibility of joint CU action. The balance-of-payments constraint is unlikely to be equal for both 1 and 2 . Accordingly, the general policy of combating unemployment within the $\mathrm{CU}$ may be constrained once full employment is reached in one partner. However, the existence of such a problem merely points to the need 
for the possibility of expenditure-switching policies between the member states - at least until the time when factor mobility is sufficient to reduce the scale of the problem to be amenable to the type of 'regional' policies currently attempted within many nations. However, it is not at all clear why devaluation should not be the obvious way of pursuing this, or if constraints on the possibility or effectiveness of devaluation are introduced, why it would be that the unilateral use of barriers to trade offers scope for greater success.

Let us finish this analysis by emphasising the problems involved. Of course, this argument does nothing to negate the general conclusion of the orthodox analysis. Real problems do exist in identifying and in agreeing on optimal policies and it may be that constraints on national policy choice within the union and/or distributive problems cause one member to be able to gain from withdrawal from the union in order to pursue less-constrained national policies. Moreover, and equally, given the assumed existence of constraints on the use of domestic and exchange-rate policies to achieve full employment, the model points to the general potential superiority of continued union membership over a policy of withdrawal.

\section{Conclusion}

Although the macroeconomic framework can teach us a lot about the contemporary economy, for it is clear that unemployment is very costly, it can be claimed that the macroeconomic approach is not suitable for analysing the impact of economic integration. Three reasons can be advanced to support this claim. Firstly, the assumption of a single commodity (although perfectly adequate for a consideration of macroeconomic changes which have an approximately equal impact on the prices of all goods, thus enabling the use of the composite commodity theorem) cannot cope with the changes in relative prices (hence the gains from specialisation) which accompany the establishment of a scheme of integration. Secondly, the impact of economic integration on the overall level of output and employment is negligible; therefore, there is no need to stress the employment effects of integration. This can be explained in the following manner. Because of the currency float since the mid-1970s, the overall current account deficit can be explained better in terms of macroeconomic and asset market factors rather than by trade policy: any increase in the deficit in, for example, manufactures brought about by economic integration must be largely countered by other parts of the trade account; thus integration changes the composition of the 
account rather than its overall level. Thirdly, the Keynesian approach completely discards the reality that people seek more foreign goods (variety leading to an increase in real income), thus missing the essence of trade policy.

Let us respond to such claims. Firstly, as the monetary approach to the balance of payments clearly demonstrates, devaluation is a temporary measure for correcting trade imbalances; therefore it is no alternative to deflation. Secondly, the currency float since the mid-1970s has not, strictly speaking, been truly free, rather it has been a managed ('dirty') float. Thirdly, as demonstrated in this paper, the macroeconomic approach is quite capable of dealing with a variety of products; hence the composite commodity theorem is equally applicable here. Finally, provided it is valid to incorporate the composite commodity theorem in the Keynesian framework, it follows that the preference for variety has not been passed over. However, be that as it may, we are simply suggesting that the macroeconomic approach should be seen as an addition to furthering our understanding of the economic integration process rather than a complete alternative to the general equilibrium analysis; we are not discarding orthodoxy, rather supplementing it.

Finally, although it may appear misplaced, we believe that it is appropriate to bring the conclusion to an end by addressing a couple of issues which may have gone amiss. The first is with regard to whether the country that withdraws from the customs union is a 'small' or 'large' nation, since if it is the latter there would be an impact on relative prices, i.e. on the terms of trade. The response would be that, given the nature our model, this is really not an issue at all. This is because we have assumed that the common external tariffs after withdrawal from the customs union remain intact; hence neither the trade relationships between the two nations concerned nor with them and the outside world are impacted upon. Also, as mentioned on several appropriate occasions, we have assumed away retaliation by the outside world because allowing for such a possibility would take us beyond our constraints of a 'simple' model. Nevertheless, allowing for retaliation would still not clarify the issue since retaliation itself can take several forms and can come from both big and small countries. Therefore, it may prove wise for us to claim that our model is 'neutral' in this respect.

The second concerns the 'nature' of our 'composite product'. One may be perfectly justified in claiming that in using 'product' our model is heavily slanted towards manufactures; hence cannot cope with the 'services' sector, which in the case of the UK is of crucial importance, where financial services contribute about one- 
tenth of the country's national income. Indeed, although for a very long time British businesses, as represented by the Confederation of British Industries (CBI) and financial sector, in the form of 'the City', have consistently advocated continued UK membership of the EU, they have recently turned against. This is specially so for the City because it fears that a possible pan-EU legislation in (financial) services may choke (or is this too strong a word?) the City's liberty and very successful and expanding general operations, which are to the detriment of New York due to the United States' litigious climate and Sarbanes-Oxley Act. Our response would be to repeat that the macroeconomic approach is capable of dealing with a 'variety of products', where term products can be embracive; thus including 'services'. Of course, where services are traded and subject to tariffs then our model automatically caters for them.

\section{Acknowledgements}

Without in any way implicating, we wish to express our thanks to Professor Philip Arestis of Cambridge University for his endorsement of our model and to an anonymous referee for insightful comments and helpful suggestions.

Received 15 January 2007, Accepted 29 October 2007

\section{References}

Armington, P. S. (1969), 'A theory of demand for products distinguished by place of production', IMF Staff Papers, 56, 159-76.

El-Agraa, Ali M. (1979a), 'On optimum tariffs, retaliation and international cooperation', Bulletin of Economic Research, 31, 46-53.

El-Agraa Ali M. (1979b), 'Common markets in developing countries', in J. K. Bowers, (ed.), Inflation, Development and Integration, Leeds University Press, Leeds, 135-48.

El-Agraa, Ali M. (1981), 'Customs unions in developing countries', in Ali M. El-Agraa and A. J. Jones, Theory of Customs Unions, Philip Allan, Oxford, 86-102.

El-Agraa, Ali M.(1989), The Theory and Measurement of International Economic Integration, Macmillan, London.

El-Agraa, Ali M. (1998), Economic Integration Worldwide, Macmillan, London.

El-Agraa, Ali M. (1999), Regional Integration: Experience, Theory and Measurement, Macmillan, London.

El-Agraa, Ali M. (ed.) (2007), The European Union: Economics and Policies, Cambridge University Press: Cambridge. 
El-Agraa, Ali M., and Jones, A. J. (1981), Theory of Customs Unions, Philip Allan, Oxford. Jones, A. J. (1982), 'A macroeconomic framework for customs union theory', Leeds Discussion Paper, 112.

McMillan, J. and McCann, E. (1981), 'Welfare effects in customs unions', Economic Journal, vol. 91,

Minford, P., Mahambare, V. and Nowell, E. (2005), Should Britain Leave the EU?, Edward Elgar, Cheltenham, UK.

Verdoorn, P. J., and Schwartz, A. N. R. (1972), 'Two alternative estimates of the effects of EEC and EFTA on the pattern of trade', European Economic Review, vol. 3, 291335 . 